\title{
Structural and functional responses of benthic invertebrates to imidacloprid in outdoor stream mesocosms
}

\author{
J.L.T. Pestana $^{\mathrm{a}, \mathrm{b}, *}$, A.C. Alexander ${ }^{\mathrm{b}}$, J.M. Culp ${ }^{\mathrm{b}}$, D.J. Baird ${ }^{\mathrm{b}}$, A.J. Cessna ${ }^{\mathrm{c}}$, A.M.V.M. Soares $^{\mathrm{a}}$ \\ ${ }^{a}$ CESAM E Departamento de Biologia, Universidade de Aveiro, Campus Universitário de Santiago, 3810-193 Aveiro, Portugal \\ ${ }^{\mathrm{b}}$ Environment Canada at Canadian Rivers Institute, Department of Biology, University of New Brunswick, 10 Bailey Drive, Fredericton, NB, Canada \\ ${ }^{\mathrm{c}}$ Environment Canada, National Hydrology Research Centre, 11 Innovation Boulevard, Saskatoon, SK, Canada \\ Combining organism-level responses with community-level processes for the evaluation and prediction of pesticide effects on stream ecosystems.
}

\section{A R T I C L E I N F O}

\section{Article history:}

Received 12 November 2008

Received in revised form

16 March 2009

Accepted 20 March 2009

\section{Keywords:}

Insecticide

Community responses

Sub-lethal effects

Leaf decomposition

In situ feeding assay

\begin{abstract}
A B S T R A C T
Structural and functional responses of a benthic macroinvertebrate assemblage to pulses of the insecticide imidacloprid were assessed in outdoor stream mesocosms. Imidacloprid pulses reduced invertebrate abundance and community diversity in imidacloprid-dosed streams compared to control streams. These results correlated well with effects of imidacloprid on leaf litter decomposition and feeding rates of Pteronarcys comstocki, a stonefly, in artificial streams. Reductions in oxygen consumption of stoneflies exposed to imidacloprid were also observed in laboratory experiments. Our findings suggest that leaf litter degradation and single species responses can be sensitive ecotoxicological endpoints that can be used as early warning indicators and biomonitoring tools for pesticide contamination. The data generated illustrates the value of mesocosm experiments in environmental assessment and how the consideration of functional and structural endpoints of natural communities together with in situ single species bioassays can improve the evaluation and prediction of pesticide effects on stream ecosystems.
\end{abstract}

(c) 2009 Elsevier Ltd. All rights reserved.

\section{Introduction}

The use of imidacloprid, a neonicotinoid is currently increasing faster than other insecticides such as carbamates, organophosphates and pyrethroids, mainly due to their excellent plant systemic activity coupled with the reduced effectiveness of other neuroactive insecticides (Matsuda et al., 2001; Tomizawa and Casida, 2005). Imidacloprid acts on the target species through ingestion or direct contact, blocking the nicotinergic neuronal pathway (Matsuda et al., 2001; Tomizawa and Casida, 2005). Nicotinergic receptors are more abundant in insects than in warmblooded animals and, thus, neonicotinoids exhibit selective toxicity towards insects (Tomizawa and Casida, 2005). Imidacloprid is used worldwide as an agricultural insecticide to control sucking and mining pests, as a flea control agent for domestic pets, and is also used in urban areas for the control of turf pests in golf courses, parks and household lawns (CCME, 2007; Fossen, 2006). Due to its persistence in soil (half-life of 48-190 days), high solubility

\footnotetext{
* Corresponding author. CESAM \& Departamento de Biologia, Universidade de Aveiro, Campus Universitário de Santiago, 3810-193 Aveiro, Portugal. Tel.: +351 234 370972; fax: +351234372587.

E-mail addresses: jpestana@ua.pt (J.L.T. Pestana), alexa.alexander@unb.ca (A.C. Alexander), jculp@unb.ca (J.M. Culp), djbaird@unb.ca (D.J. Baird), asoares@ ua.pt (A.J. Cessna), asoares@ua.pt (A.M.V.M. Soares).
}

(514 $\mathrm{mg} / \mathrm{L}$ at $20^{\circ} \mathrm{C}$ ) and low octanol water partition coefficient ( $\mathrm{Log}$ Kow $=0.57$ ) make it a potential contaminant of surface and ground waters through drift, dissolved runoff or leaching (CCME, 2007; Fossen, 2006; Gupta et al., 2002). Imidacloprid is increasingly being found in aquatic systems especially during rainfall events with levels in runoff from Canadian agricultural areas reaching concentrations of up to $11.9 \mu \mathrm{g} / \mathrm{L}$ (CCME, 2007).

Single species toxicity tests in the laboratory have already shown that imidacloprid is toxic to fish at relatively high concentrations ( $\mathrm{LC}_{50}$ higher than $100 \mathrm{mg} / \mathrm{L}$ ) and can be extremely toxic at low concentrations ( $\mathrm{LC}_{50}$ of $0.65-65 \mu \mathrm{g} / \mathrm{L}$ ) to several species of aquatic invertebrates, especially insects (CCME, 2007). However, such laboratory single species assays are insufficient to fully assess ecological risks, for several reasons (Crane, 1997): (i) the responses of species tested in standard toxicity tests may not fully encompass the responses of the diversity of species found in natural systems; (ii) it is difficult to extrapolate from laboratory results to conditions occurring in nature, which encompass a wider range of habitat conditions than those found in the laboratory; (iii) it is difficult to present the full range of relevant exposure routes in the laboratory since modern insecticides, tend to break down rapidly and are applied in low doses (Boxall et al., 2002; Caquet et al., 2007; Crane, 1997). It is thus important to consider higher-tier experiments to assess the effects of these substances on aquatic ecosystems (Fairchild et al., 1992; Boxall et al., 2002). 
The use of controlled semi-field exposures, such as mesocosms, provides an opportunity to perform ecosystem-level research that can complement laboratory bioassays and, therefore, better predict effects of ecological relevant exposures of different types of anthropogenic substances to natural communities (Fairchild et al., 1992; Culp et al., 2003; Hickey and Golding, 2002; Van den Brink, 2006; Van den Brink et al., 2005). Mesocosms are smaller and less complex than natural ecosystems, yet they allow the use of relevant biological conditions (ambient abundance of natural biota), while maintaining the statistical power through replication of treatments and precise regulation of pesticide concentrations and other physico-chemical variables (Baird et al., 2001; Crane, 1997). Since sub-lethal, population-level responses are of great significance to natural ecosystems, it is important to consider the application of in situ bioassays to obtain reliable and sensitive measures of pesticide effects (Maltby, 1999; Slijkerman et al., 2004). In situ bioassays deployed within semi-field experiments have the advantage of testing selected species under realistic field conditions compared to laboratory tests and provide a mechanistic explanation of effects by linking organism-level physiological or behavioural responses and community functional parameters (Caquet et al., 2007; Coors et al., 2006; Hruska and Dube, 2004; Kreutzweiser et al., 2007). The use of the mesocosm approach in combination with experimental tests covering functional and structural endpoints at various levels of biological organisation can help identify causal mechanisms responsible for direct and indirect effects of pesticide contamination on natural communities and ecosystem functions (Baird et al., 2001; Mills and Semlitsch, 2004; Relyea et al., 2005; Rohr et al., 2006; Slijkerman et al., 2004).

This paper describes the effects of pulsed exposure to Admire ${ }^{\circledR}$ (imidacloprid; Bayer CropScience; Calgary, AB, Canada) on structural and functional measures of benthic invertebrate communities, as this best reflects the edge-of-field scenario for runoff of this substance (CCME, 2007). This was achieved using field deployed artificial stream mesocosms inoculated with natural substratum and a portion of an extant riverine benthic community. Endpoints for the assessment included benthic invertebrate abundance and composition and leaf litter degradation. The sensitivity and relevance of organism-level responses to stress caused by pulses of imidacloprid were also assessed with the North American stonefly, Pteronarcys comstocki Smith, through feeding bioassays deployed in mesocosms systems together with laboratory measures of metabolic rate (as oxygen consumption). Pteronarcid stoneflies can be easily identified, have a long life cycle (3-4 years) which allows for the collection of similar size individuals in the field which can be easily transported and acclimatised to laboratory conditions. Pteronarcyids are detritivore shredders, feeding primarily on leaf litter and have a relatively high sensitivity to pollutants (Cole et al., 2001; Merrit and Cummins, 1996; Pesacreta, 1997; Ruesink and Srivastava, 2001). Here we link stonefly feeding responses (in situ deployment); respiration rates (laboratory) and benthic invertebrate responses to low ( $2 \mathrm{ug} / \mathrm{L})$ and high $(20 \mathrm{ug} / \mathrm{L})$ imidacloprid exposure

\section{Material and methods}

\subsection{In situ feeding bioassay}

P. comstocki nymphs of similar size were collected from Nashwaak River, New Brunswick, Canada and acclimated to laboratory conditions $\left(20{ }^{\circ} \mathrm{C}\right.$ in aerated groundwater and under a 14L/10D light regime). Larvae were fed ad libitum with alder leaves for one week prior to the experiment. For each treatment, 15 P. comstocki nymphs (average length $20.00 \mathrm{~mm}+/-1.79 \mathrm{SD}$ ) were allocated to individual cylindrical cages $(5 \mathrm{~cm} \times 5 \mathrm{~cm})$ that were capped at both ends with $1 \mathrm{~mm}^{2}$ mesh. The cages contained food in the form of 5 alder leaf discs of known dry weight and a pebble to provide a hard surface substrate for the organisms. The cages were deployed in the outflow of the corresponding mesocosm treatment in plastic containers in order to expose the cages to similar environmental conditions (e.g., temperature, luminosity) as in the artificial streams (Fig. 1C and D).

Leaf discs used in feeding experiments were autoclaved, conditioned for 20 days at $20^{\circ} \mathrm{C}$ in aerated stream water with leaf litter collected from the Nashwaak River, then dried for 4 days at $60{ }^{\circ} \mathrm{C}$ and the dry mass of leaf discs determined. To prevent breakage and to favour softening leaf discs inside cages were soaked for $48 \mathrm{~h}$ in groundwater used in the mesocosm experiment prior to the feeding trials. After the 20-day exposure period, animals and the remaining food were removed, dried at $60{ }^{\circ} \mathrm{C}$ for 4 days and reweighed. Feeding rate was calculated as the difference between the initial and final dry mass ( $\mathrm{mg}$ ) of leaf discs and divided by elapsed time (20 days). Five control cages per treatment that contained leaf discs, but no animals, were used to correct for weight change due to factors other than feeding.

\subsection{Leaf litter degradation}

Green Alder leaves (Alnus sp.) were collected, autoclaved and then conditioned by keeping them for 20 days at $20^{\circ} \mathrm{C}$ in aerated stream water and leaf litter collected from the Nashwaak River. Leaf bags $(10 \times 10 \mathrm{~cm})$ were constructed by placing $1 \pm 0.01 \mathrm{~g}$ of air dried leaves in coarse mesh plastic bags (mesh size $1 \mathrm{~cm}$ ) for determination of decomposition of leaf material from invertebrate feeding and microbial activity and fine mesh plastic bags (size $0.250 \mathrm{~mm}$ ) to assess microbial decomposition of leaf material. One coarse and one fine leaf bags were placed in every stream after inoculation of the substratum (Fig. 1B). After 20 days leaf bags were collected, returned to the laboratory in plastic bags and stream water. Invertebrates and particulate organic debris were gently removed from the leaf material by washing with distilled water and gentle agitation with a soft brush. The leaf material was dried at $60^{\circ} \mathrm{C}$ for $96 \mathrm{~h}$ and weighed. Five extra leaf bags were used to determine initial air dry weight to oven dry weight (4 days at $60{ }^{\circ} \mathrm{C}$ ) conversion factor. The leaf oven dry mass remaining was used to calculate the exponential decay coefficient ( $k$; i.e., decomposition rate) (Petersen and Cummins, 1974).

\subsection{Laboratory measurements of oxygen consumption}

The effect of insecticide exposure on oxygen consumption was assessed using 10 $P$. comstocki nymphs per treatment (average length $19.98 \mathrm{~mm}+/-1.39 \mathrm{SD}$ ). Organisms were exposed in laboratory tanks to the appropriate pesticide solutions $(0,2,10$ and $20 \mu \mathrm{g} / \mathrm{L})$ and no food for $20 \mathrm{~h}$ before the respiration trials

Oxygen consumption was then determined by simple static respirometry, using larvae held for $4 \mathrm{~h}$ in 50-ml gas-tight syringes (Hamilton, USA). Syringes were filled with the same test solutions and organisms and the remaining air was expelled from each syringe before they were placed in a water bath $\left(20^{\circ} \mathrm{C}\right)$ in the dark for $4 \mathrm{~h}$ giving thus a total of $24 \mathrm{~h}$ of exposure.

Initial and final oxygen concentrations were measured with an oxygen meter (model 782, with an oxygen electrode model 1302, Strathkelvin Instruments, Glasgow). After exposure, larvae were dried at $60{ }^{\circ} \mathrm{C}$ for 4 days and their mass was determined. Oxygen consumption was estimated from the difference between the oxygen content of water before $\left(T_{0}\right)$ and after $\left(T_{\text {final }}=4 \mathrm{~h}\right.$ ) of the respiration trial period, with respiration rate expressed as $\mu$ g oxygen consumed per mg of organism per hour. Due to the limited number of syringes available, this experiment was performed in two runs over two consecutive days using half the replicates for every treatment each day (randomised block design).

\subsection{Mesocosms treatments and set-up}

The mesocosm experiment was conducted for 20 days in August 2005 and included a treatment to examine the effects of three pulses (24-h duration) of imidacloprid (2, and $20 \mu \mathrm{g} / \mathrm{L}$ ) every 7 days on the macroinvertebrate community.

The partial flow-through mesocosms (Fig. 1A and B) were deployed at the Agriculture and Agri-Foods Canada facility adjacent to the Saint John River, approximately $10 \mathrm{~km}$ southeast of Fredericton, New Brunswick, Canada. The artificial streams were designed to simulate lotic habitats by encompassing a portion of substratum and of the benthic invertebrate community collected in the Nashwaak River, New Brunswick, Canada (46 $14294^{\prime} \mathrm{N}, 66^{\circ} 36722^{\prime} \mathrm{W}$ ) in semi-field conditions (Culp et al., 2003; Culp and Baird, 2006). A complete description of the artificial streams characteristics, inoculation of fine and coarse natural substratum and pesticide contamination can be found elsewhere (Alexander et al., 2008)

Once inoculated with natural substratum and after deploying the leaf bags (see above), the streams were allowed to equilibrate for 2 days prior to the addition of benthic invertebrates. Benthic invertebrates were collected upstream of the gravel collection site on the Nashwaak River with U-nets (area $=0.06-\mathrm{m}^{2}$ ) (Scrimgeour et al., 1993). Five U-nets were collected, pooled and subsampled into four equal portions, this procedure being repeated twice thereby producing 16 replicate samples. These invertebrate assemblage subsamples were randomly assigned and inoculated into replicate streams (one per treatment table) resulting in a similar invertebrate assemblage in the replicate streams. Initial densities in experimental streams were approximately $10 \%$ higher than ambient field density of aquatic invertebrates in order to offset mortality resulting from handling and transport from the river to the mesocosm test site. Once inoculated with invertebrates, the streams were permitted to equilibrate for 1 day before beginning the insecticide exposures. 

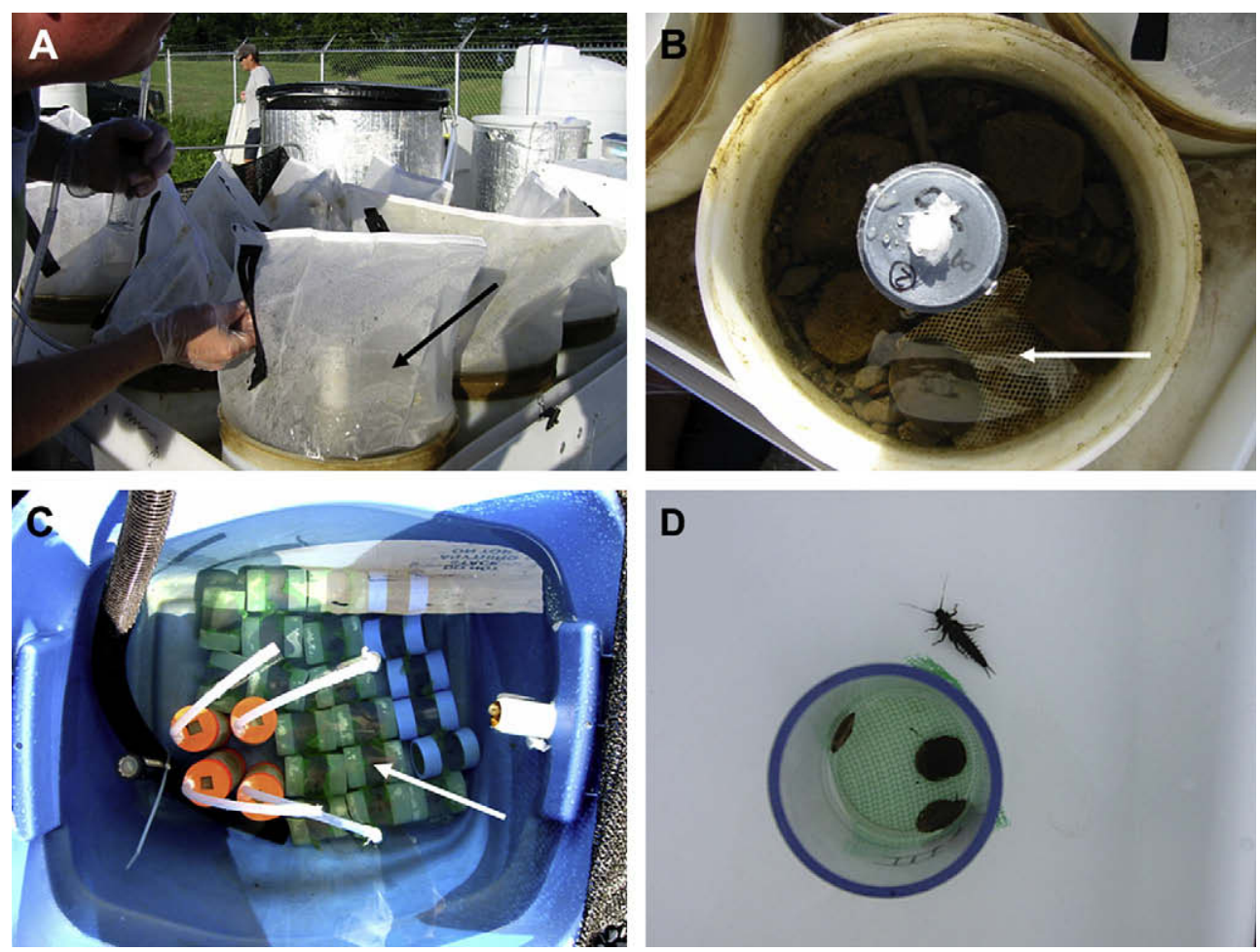

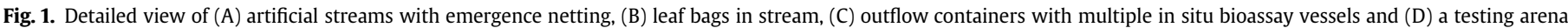
used in the stonefly feeding bioassay.

Imidacloprid solution was mixed in a stock tank by diluting an aliquot of Admire ${ }^{\circledR}$ (240 g imidacloprid/L).

At the end of the 20 days the contents of replicate streams were sieved and water samples, periphyton samples and invertebrates were collected from each replicate stream. Organisms found in the leaf bags were collected and combined with benthic samples from the respective stream replicates.

Imidacloprid concentration in each treatment was determined by chemical analyses conducted at an Environment Canada laboratory in Saskatoon, SK, Canada using a Micromass Quattro Ultima liquid chromatography mass spectrometer (LC-MS) equipped with a stainless steel column $(100 \times 2.2 \mathrm{~mm}$; MS Xterra C-8; $100 \times 2.2 \mathrm{~mm}$; Waters, Milford, MA, U.S.A.). Samples for imidacloprid analyses were taken from each mesocosm table at the onset, during and at the end of the imidacloprid pulse. These samples were collected in $1 \mathrm{~L}$, amber vials (EPA vials; Fisher scientific; Fair Lawn, NJ, U.S.A.) and stored at $4{ }^{\circ} \mathrm{C}$ until shipment to the laboratory. This methodology allowed quantification of imidacloprid to a level of precision of $0.01 \mu \mathrm{g} / \mathrm{L}$.

\subsection{Macroinvertebrate community responses}

At the end of the experimental period, i.e. after 20 days, benthic invertebrates were collected by washing the entire contents of each stream through a $250-\mathrm{mm}$ sieve, and preserving the collected organic material and invertebrates in $10 \%$ formalin. Macroinvertebrates were counted and identified to Family level (Ephemeroptera, Plecoptera, Trichoptera, Diptera and Coleoptera) or Order (Oligochaeta, Nematoda and Collembola) in the laboratory. Adult insects were removed from the emergent traps with the aid of an aspirator every second day of the experiment and preserved for identification.

The family biotic index, including tolerance values for non-insect macroinvertebrates (Barbour et al., 1989; Mandaville, 2002) was calculated to assess its discriminatory sensitivity towards pesticide contamination.

FBI was calculated as:

$\mathrm{FBI}=\sum \frac{x_{i} t_{i}}{n}$

where " $x_{i}$ " is the number of individuals in the "ith" taxon, " $t_{i}$ " is the tolerance value of the "ith" taxon, and " $n$ " is the total number of organisms in the sample.

Simpson's diversity index,

$\mathrm{DI}=1-\sum_{i=1}^{s}\left(p^{i}\right)^{2}$ where $p_{i}$ is the proportion of individuals of family $i, N$ is the total number of individuals and $s$ the total number of families, was also calculated as a measure of heterogeneity and gives the probability of two individuals chosen at random and independently from the population belonging from different families.

The Community Loss Index (CLI) measures the loss of benthic taxa in a study site with respect to a reference site. Values increase from 0 as the degree of dissimilarity between the sites increases (Mandaville, 2002). CLI was calculated as:

$\mathrm{CLI}=\frac{d-a}{e}$

where " $a$ " is the number of taxa common to both replicate streams, " $d$ " is the total number of taxa present in the reference stream, and " $e$ " is the total number of taxa present in the pesticide treated stream. In this study, CLI was determined by comparing the total number of taxa present in each stream replicate of each imidacloprid concentration ("e") to the number of taxa present in each of the respective stream replicate of the control treatment ("d"). The average value for the different streams in the control was calculated comparing all four streams of the control with each other in all possible combinations. This was done to account for the variation of the subsampling strategy utilized. We have not considered the insect pupae or the unidentified early instars of organisms for the calculation of biotic indexes or richness measures.

\subsection{Data analysis}

One-way analysis of variance, with individual stream mesocosms as replicates, was used for analysis of all variables. One-way analysis of variance was also used to compare feeding and respiration of $P$. comstocki among the different imidacloprid concentrations. For respiration rates, day of measurement was blocked as a random factor. Whenever significant differences were observed, Dunnett post hoc tests were used for multiple comparisons to determine which treatments were significantly different from the control. Invertebrate density data was $\log (x+1)$ transformed to stabilise variances across treatments (Zar, 1996), although untransformed data were used for the calculation of biotic indices. Analysis of variance was performed with the MINITAB 13.0 statistical package (Minitab, 2000).

\section{Results}

Imidacloprid average peak concentrations $( \pm 1 \mathrm{SE})$ measured during the $24 \mathrm{~h}$ pulses were $1.63 \mu \mathrm{g} / \mathrm{L}( \pm 0.15$ ) for the low concentration and $17.60 \mu \mathrm{g} / \mathrm{L}( \pm 1.82)$ for the high concentration. Average 
temperatures $( \pm 1 \mathrm{SE})$ were $14.7^{\circ} \mathrm{C}( \pm 0.23)$ for control table, $14.5^{\circ} \mathrm{C}$ $( \pm 0.24)$ for the treatment with low imidacloprid concentration and $14.9{ }^{\circ} \mathrm{C}( \pm 0.24)$ for the treatment with high imidacloprid concentration. Feeding bioassay results for the control treatment were obtained using cages deployed in the outflow of a different table (a second control treatment) with slightly higher mean daily temperature: $15.5{ }^{\circ} \mathrm{C}( \pm 0.41)$ due to problems with a peristaltic pump. The replicates from this mesocosm treatment were not included in the analysis of macroinvertebrate community or leaf decomposition.

\subsection{Effects of imidacloprid on macroinvertebrate community}

By day 20 , the macroinvertebrate community was dominated by insects in all treatments (more than 92\% in all streams). From these, Heptageniidae (Ephemeroptera), Lepidostomatidae, Hydropsychidae and Helicopsychidae (Trichoptera), chironomids, dipteran pupae and elmidae beetles were all present at high densities in untreated control streams. The non-insect taxa were of only minor importance except for oligochaetes which made up less than $3 \%$ of the total numbers of organisms in the control treatment.

Imidacloprid pulses reduced benthic invertebrate abundance and community diversity in imidacloprid-dosed streams compared to control streams (Table 1). The community loss index, but not Simpson's index, total or EPT (Ephemeroptera, Plecoptera and Tricoptera) richness, showed a significant increase which reflects a significant reduction in diversity caused by imidacloprid exposure. The family biotic index observed for imidacloprid treatments was not significantly different from the control treatment (Table 1).

Imidacloprid had an adverse effect on benthic communities with ca. of 5 and $42 \%$ reductions in the abundance of invertebrates exposed to pulses of low and high $\mu \mathrm{g} / \mathrm{l}$ imidacloprid concentrations (Table 1, Fig. 2). In the high concentration treatment there was a clear reduction of total benthic insects (ANOVA $F_{2,11}=6.40$, $p=0.019$ ). Fifty-five and $67.7 \%$ average reductions in abundance were observed for Plecoptera (ANOVA $F_{2,11}=6.52, p=0.018$,) and Ephemeroptera (ANOVA $F_{2,11}=6.86, p=0.016$ ) in streams exposed to high concentrations of imidacloprid, giving an overall average reduction in abundance of EPT taxa of 69\% (ANOVA $F_{2,11}=6.40$, $p=0.019$ ). A 70\% average abundance reduction in response to high imidacloprid concentration treatments was also observed for Trichoptera but this reduction was not statistically significant (ANOVA $F_{2,11}=2.52, p=0.135$ ) (Fig. 2).

Coleoptera were less affected (28.6\% reduction in high imidacloprid concentration treatments) (ANOVA $F_{2,11}=0.63, p=0.554$ ) and no significant effects of imidacloprid were observed for dipterans collected from the streams after 20 days (ANOVA $F_{2,11}=1.62, p=0.251$ ) (Fig. 2). Oligochaetes also showed high

\section{Table 1}

Comparison of benthic invertebrate community endpoints (mean $\pm \mathrm{SE}$ ) in response to different imidacloprid concentrations.

\begin{tabular}{|c|c|c|c|c|c|c|}
\hline & \multicolumn{6}{|c|}{ Imidacloprid nominal concentrations } \\
\hline & 0 & $1.63 \mu \mathrm{g} / \mathrm{L}$ & $17.60 \mu \mathrm{g} / \mathrm{L}$ & $\mathrm{D} f$ & $F$ & $\mathrm{P}$ \\
\hline Density (no./stream) & $310 \pm 45$ & $296 \pm 94$ & $177 \pm 19^{d}$ & 2.11 & 8.26 & 0.009 \\
\hline Total richness & $21 \pm 1$ & $19 \pm 2$ & $16 \pm 1$ & 2.11 & 3.24 & 0.087 \\
\hline EPT richness & $12 \pm 1$ & $12 \pm 1$ & $9 \pm 1$ & 2.11 & 3.31 & 0.084 \\
\hline EPT/chironomids & $1.65 \pm 0.45$ & $0.97 \pm 0.20$ & $0.49 \pm 0.13$ & 2.11 & 3.90 & 0.060 \\
\hline Simpson's $\mathrm{DI}^{\mathrm{a}}$ & $0.74 \pm 0.05$ & $0.72 \pm 0.05$ & $0.55 \pm 0.09$ & 2.11 & 2.74 & 0.118 \\
\hline $\mathrm{mFBI}^{\mathrm{b}}$ & $4.77 \pm 0.52$ & $5.44 \pm 0.19$ & $6.23 \pm 0.40$ & 2.11 & 3.43 & 0.078 \\
\hline $\mathrm{CLI}^{\mathrm{c}}$ & $0.22 \pm 0.03$ & $0.22 \pm 0.04$ & $0.47 \pm 0.04^{\mathrm{d}}$ & 2.19 & 10.00 & $<0.001$ \\
\hline
\end{tabular}

\footnotetext{
a Simpson's DI: Simpson diversity index.

b FBI: modified Hilsenhoff's family biotic index.

c CLI: Community loss index.

d Treatments significantly different from control.
}

sensitivity to these high imidacloprid concentrations with a $75 \%$ reduction in density in the high concentration treatments (ANOVA $F_{2,11}=13.12, p=0.002$ ). The lowest concentration of imidacloprid tested caused a reduction of $30 \%$ on EPT taxa abundance, similar to the effect on caddisflies and approximately two times the effect observed for mayflies. The effects of pulses of low concentrations of imidacloprid were not significantly different for any of the parameters tested (Table 1, Fig. 2).

\subsection{Effects of imidacloprid on leaf litter}

There was no evidence that imidacloprid at either test concentration inhibited microbial decomposition rates. Mass loss in fine mesh bags at all test concentrations did not differ significantly from controls (ANOVA $F_{2,11}=0.80, p=0.478$; Fig. 3 ). In contrast, total decomposition of leaf material in coarse mesh bags (a combination of invertebrate feeding and microbial decomposition) was significantly reduced in treated streams and significantly lower in the highest imidacloprid concentrations, compared to control streams (ANOVA $F_{2,11}=4.95, p=0.035$; Fig. 3 ).

\subsection{Effects of imidacloprid on stonefly in situ and laboratory bioassays}

In the feeding and respiration experiments, observed mortality was always below $10 \%$. The feeding rate of $P$. comstocki exposed to outflow water from the mesocosm systems was reduced in imidacloprid exposure tables ( 27 and $71 \%$ in low and high imidacloprid concentration pulses, respectively). Significantly different feeding rates were observed for the higher concentration treatment (ANOVA $F_{2,44}=14.34, p<0.001$; Fig. 4 ).

$P$. comstocki showed reductions in oxygen consumption when exposed in the lab for $24 \mathrm{~h}$ to imidacloprid, but this was significant only at nominal concentrations of $10 \mu \mathrm{g} / \mathrm{L}$ or greater (ANOVA $F_{3,39}=33.66, p=0.008$; Fig. 5). No significant effect was observed for day of measurement (ANOVA $F_{1,39}=4.41, p=0.126$ ) or interaction of both factors (ANOVA $F_{3,39}=2.14, p=0.114$ ). Actual concentrations of imidacloprid although not measured are not expected to differ considerably from the nominal concentrations because we used the same stock solution used for mesocosm experiments and the exposure for these measurement of oxygen consumption were performed in the dark which substantially reduces the degradation of imidacloprid.

\section{Discussion}

The aim of our study was to produce a more robust examination of ecological risk of exposure to the insecticide, imidacloprid, by integrating community assemblage effects obtained in field mesocosms with effects determined in functional bioassays conducted in the laboratory and mesocosms. This integration of structural and functional approaches to ecological risk assessment is particularly relevant for the assessment of toxic chemicals with short half lives that are most likely to be at effect-concentrations during brief exposure periods (e.g. pulses during runoff events). Evidence generated by this approach can help to minimise the uncertainty of extrapolation from laboratory results to natural ecosystems (Van den Brink, 2006). Specifically, we assessed the effects of multiple pulses of different concentrations of imidacloprid on benthic invertebrates. By including data from an in situ ecotoxicological bioassay to complement information on the structure of the macroinvertebrate community and functional parameters, the methodology presented here can help establish mechanistic links between effects at various levels of ecological organization, thereby 

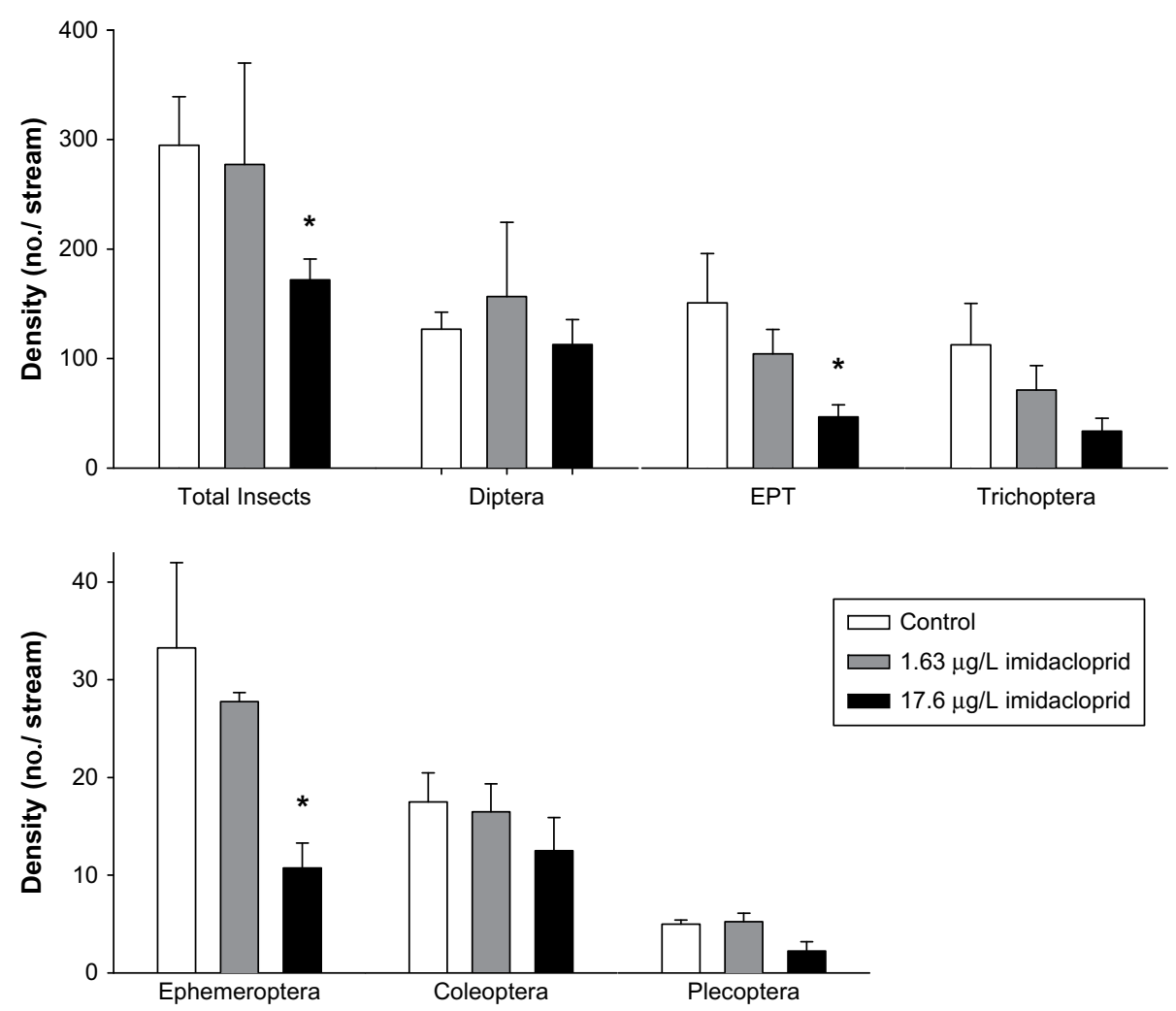

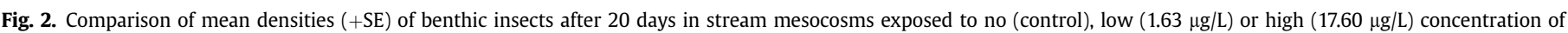

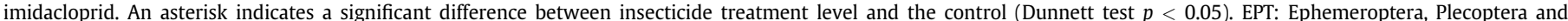
Trichoptera.

improving our ability to assess direct and indirect effects of pesticide contamination on ecosystem functioning.

We demonstrated significant effects of imidacloprid pulses on abundances of invertebrates, EPT taxa and oligochaetes at concentrations of $17.60 \mu \mathrm{g} / \mathrm{L}$. Aquatic Coleoptera appear to be more tolerant to imidacloprid than other insects, which is unexpected given that imidacloprid is used to control terrestrial coleopteran pest species. Previous research indicates that imidacloprid can be toxic to non-insect freshwater taxa: Hyallella azteca $96 \mathrm{~h}-\mathrm{LC}_{50}$ of 17-65 $\mu \mathrm{g} / \mathrm{L}$, (Stoughton et al., 2008) Lumbriculus variegatus 96 h-EC 50 of $6.2 \mu \mathrm{g} / \mathrm{L}$, (Alexander et al., 2007), as well as to insects (i.e., dipterans, caddisflies, mayflies) in the range of $0.65-50 \mu \mathrm{g} / \mathrm{L}$ (Pestana et al., unpublished-a; Song et al., 1997; Stoughton et al., 2008). Mayflies are particularly sensitive (Epeorus longimanus 96 h-LC 50 of $0.65 \mu \mathrm{g} / \mathrm{L}$, Alexander et al., 2007).

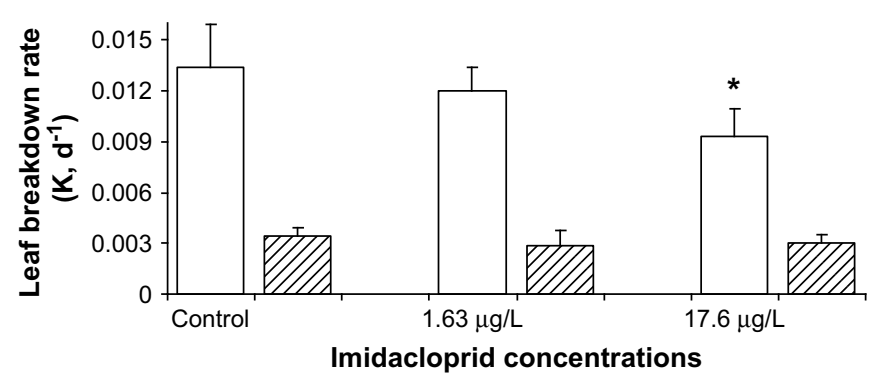

Fig. 3. Comparison of leaf breakdown rates (mean $+\mathrm{SE}$ ) in coarse (white bars) and fine (shaded bars) mesh litter bags after 20 days of exposure to no (control), low (1.63 $\mu \mathrm{g} / \mathrm{L}$ ) or high $(17.60 \mu \mathrm{g} / \mathrm{L})$ imidacloprid concentration. Asterisks denote imidacloprid treatments that were significantly different from the control treatment (Dunnett test, $p<0.05$ ).
In terms of toxicity of model species, Daphnia magna is much more tolerant to Admire ${ }^{\circledR}$ (imidacloprid) with a $48 \mathrm{~h}-\mathrm{LC}_{50}$ of $10.44 \mathrm{mg} / \mathrm{L}$ (Song et al., 1997) than Chironomus tentans (96 h-LC 50 of $5.40 \mu \mathrm{g} / \mathrm{L}$ ) (Stoughton et al., 2008). Chironomus riparius have also shown low tolerance to another commercial insecticide with imidacloprid as the active ingredient, Confidor ${ }^{\circledR}$ with a $48 \mathrm{~h}-\mathrm{LC}_{50}$ of $12.94 \mu \mathrm{g} / \mathrm{L}$ (Pestana et al., unpublished-a).

In addition, Pestana et al. (unpublished-a) observed that imidacloprid exposure delayed maturation for chironomids, lending support to the use of insect adult biomass or insect emergence as a functional assessment (Culp et al., 2003; Schulz and Liess, 2001). In fact, Alexander et al. (2008) showed that exposure to sub-lethal concentrations of imidacloprid caused mayflies to mature earlier at a smaller size, leading to impaired reproductive fitness.

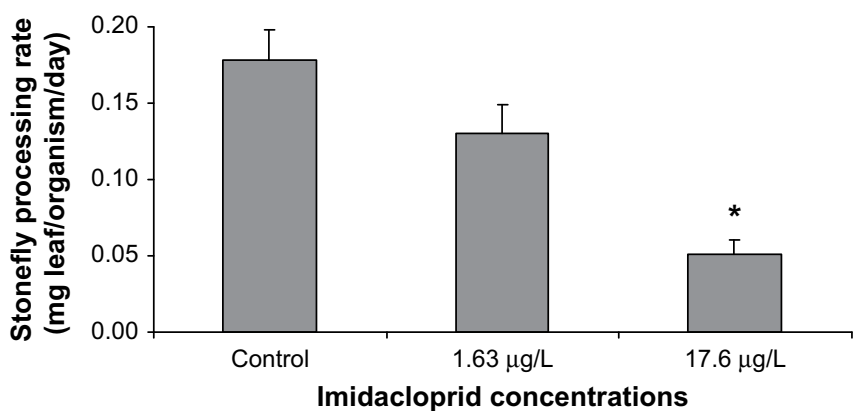

Fig. 4. In situ $P$. comstocki processing rate (mean $+\mathrm{SE}$ ) measured over 20 days in stream mesocosms exposed to no (control), low $(1.63 \mu \mathrm{g} / \mathrm{L})$ or high $(17.60 \mu \mathrm{g} / \mathrm{L})$ concentration of imidacloprid. Asterisks denote imidacloprid treatments that were significantly from the control treatment (Dunnett test, $p<0.05$ ). 


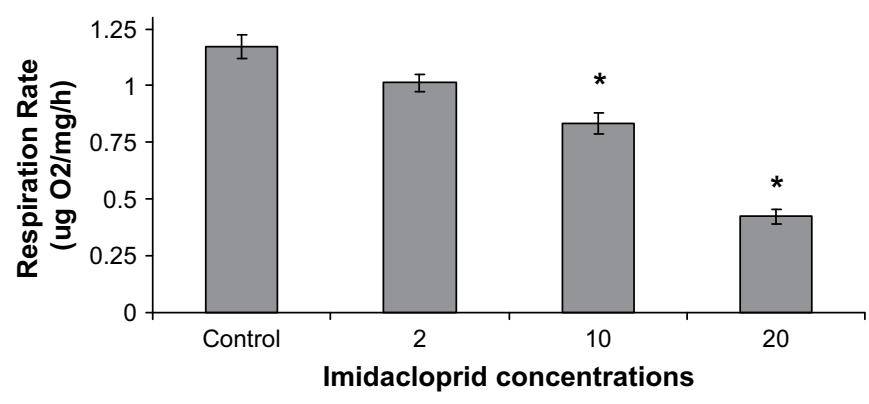

Fig. 5. P. comstockii laboratory respiration rates (mean $+\mathrm{SE}$ ) under exposure to four levels of imidacloprid concentration. Asterisks denote imidacloprid treatments that were significantly different, from control (Dunnett test, $p<0.05$ ).

Several diversity and biotic indices commonly calculated in rapid bioassessment protocols failed to discriminate effects of pesticide contamination on natural benthic communities. This result is likely related to the fact that these diversity indices place relatively little weight on rare taxa compared to common taxa (Mandaville, 2002; Rosenberg and Resh, 1993). In addition, the family biotic index uses tolerance values intended to assess organic pollution rather than sensitivity of organisms to pesticides, which can represent a disadvantage for measuring effects of toxic insecticides in insect-dominated communities (Rosenberg and Resh, 1993). This lack of sensitivity was surprising given that chironomids made a significant contribution to these indices (abundance and tolerance values), and laboratory tests that show low tolerance of chironomids to imidacloprid (Pestana et al., unpublished-a; Stoughton et al., 2008). In contrast, the community loss index, which considers taxa richness, but not abundance, showed a significant reduction in the number of taxa present under high imidacloprid exposure compared to control streams.

Our results demonstrated that pulses of imidacloprid impair feeding by $P$. comstocki on leaf material. Feeding inhibition has been reported in trichopteran species (Pestana et al., unpublished-a), daphnids (Pestana et al., unpublished-b); ephemeropterans and oligochaetes (Alexander et al., 2007) as responses to sub-lethal concentrations of imidacloprid in laboratory and of both pteronarcids and tipulids; in mesocosm experiments (Kreutzweiser et al., 2007). Neurotoxic insecticides such as imidacloprid have been shown to induce behavioural effects, including reduced activity and uncontrolled muscular contractions of insects (Matsuda et al., 2001; Moffat, 1993), which likely contributed to the feeding inhibition response. Similarly, laboratory exposures to imidacloprid induced a reduction in the respiratory rates of $P$. comstocki possibly as a consequence of reduced activity leading to the disruption of ventilatory movements and "push up behaviour" (Ericksen et al., 1996; Genkai-Kato et al., 2000). Pestana et al. (unpublished-a) observed similar reductions in oxygen consumption by caddisflies in response to imidacloprid exposure. Thus, these reductions in activity are hypothesized to reduce both the rate and efficiency of foraging, and cause reduced intake of energy by aquatic invertebrate species with consequences for growth, reproduction and survival. The results from leaf decomposition further suggest that imidacloprid can affect leaf shredding since a significant reduction in decomposition rates was observed for coarse mesh bags deployed in the artificial streams receiving pulses of high concentration of imidacloprid. In our case it was not possible to relate feeding rates of $P$. comstocki deployed in situ with abundances within the benthic communities inoculated because several stoneflies were removed from invertebrate samples to avoid predation within artificial streams. Due to the size of many pteronarcid nymphs they were wrongly considered as predators and systematically removed from invertebrate sub samples being almost absent in artificial streams.

The results from leaf decomposition further suggest that imidacloprid can affect leaf shredding since a significant reduction in decomposition rates was observed for coarse mesh bags deployed in the artificial streams receiving pulses of high concentration of imidacloprid. This also indicates that the functional role played by $P$. comstocki in the studied system correlated well with leaf processing by the natural community. By identifying invertebrates only to Family level it is difficult to determine the functional feeding role of the majority of the invertebrate community present in artificial streams, however the effects of imidacloprid on leaf decomposition observed in coarse leaf bags may be related to the high densities of lepidostomatid tricopterans (shredders) and chironomids. Chironomids, although generally considered collector-gatherers, have been shown to feed also on coarse particulate organic matter (Callisto et al., 2007).

Although we did not measure microbial community structure or activity directly, leaf decomposition in fine leaf bags was not significantly different among the imidacloprid treatments. Other studies (Kreutzweiser et al., 2007) examining effects of imidacloprid on microbial activity and decomposition have likewise reported no detectable effects in artificial systems. Together, these results show that imidacloprid does not seem to affect the microbial community directly and for this reason, the feeding inhibition by leaf-shredding insects was less likely due to a reduced microbial conditioning of leaves. Thus, although microbial colonization and conditioning of leaf litter is critical for the diet of shredders (Graça, 2001), low sub-lethal concentrations of imidacloprid most likely affects leaf litter breakdown, through impairment of the feeding behaviour of leaf-shredding invertebrates.

\section{Conclusions}

In this study the effects of pulses of imidacloprid were assessed under controlled conditions of exposure that simulated field conditions. Moreover, functional and structural endpoints were used to better understand the mechanisms of imidacloprid toxicity at an ecosystem level. The concentrations of imidacloprid tested here were expected to be within realistic environmental concentrations previously shown to occur in agricultural runoffs and our data suggest that significant adverse effects on aquatic macroinvertebrate community composition would be expected where imidacloprid concentrations in water reach or exceed $20 \mu \mathrm{g} / \mathrm{L}$ even if for short periods. Imidacloprid reaching streams or rivers at these or even lower concentrations can exert lethal and sub-lethal effects on aquatic non-target organisms (feeding inhibition, delayed maturity, size at emergence) with potential impairment of insect reproductive fitness, thus influencing critical ecosystem properties and functions.

Plant litter decomposition was tested as an indicator of imidacloprid effects in insect-dominated benthic communities, and coarse and fine mesh bags, have shown to be suitable to the application in mesocosms studies to distinguish the effects of pesticides on aquatic fungi and macroinvertebrates, the two main decomposers. In this way a useful functional endpoint can be used to complement pesticide risk assessment programs based on structural parameters providing an indication of the possible impairment in the functioning of the stream ecosystems. Feeding assays are used as chronic assays in laboratory and in the field with a wide range of organisms (Hatch and Burton, 1999; Irving et al., 2003; Lam, 1996; Maltby et al., 2002; McWilliam and Baird, 2002) and constitute sensitive biomonitoring tools to assess effects of low levels of pesticides. In situ single species feeding assays can also be used with an array of invertebrate species in mesocosms studies 
and in the field as early warning indicators of pesticide contamination. This study highlights the importance of combining fineresolution studies of individual species with model ecosystem studies and the integration of functional and structural endpoints for a better understanding of the mechanisms that link organismlevel responses to population- and community-level processes and to improve our prediction of possible sub-lethal as well as indirect effects of pesticides.

\section{Acknowledgements}

We would like to thank, Kristie Heard, Eric Luiker, Dave Hryn and Daryl Halliwell for helping with the mesocosm experiments and to Kristie Heard for the identification of macroinvertebrates. Financial support for this work was provided by Environment Canada's Pesticide Science Fund, the Portuguese Foundation for Science and Technology, through a PhD grant to João Pestana and Natural Sciences and Engineering Research Council Discovery grants to DJB and JMC.

\section{References}

Alexander, A.C., Culp, J.M., Liber, K., Cessna, A.J., 2007. Effects of insecticide exposure on feeding inhibition in mayflies and oligochaetes. Environmental Toxicology and Chemistry 26, 1726-1732.

Alexander, A.C., Heard, K.S., Culp, J.M., 2008. Emergent body size of mayfly survivors. Freshwater Biology 53, 171-180.

Baird, D.J., Brock, T.C.M., de Ruiter, P.C., Boxall, A.B.A., Culp, J.M., Eldridge, P., Hommen, U., Jak, R.G., Kidd, K.A., Dewitt, T., 2001. The food web approach in the environmental management of toxic substances. In: Baird, D.J., Burton, G.A. (Eds.), Ecological Variability: Separating Anthropogenic from Natural Causes of Ecosystem Impairment. SETAC, Pensacola, FL, USA, pp. 83-122.

Barbour, M.T., Gerritsen, J., Snyder, B.D., Stribling, J.B., 1989. Rapid Bioassessment Protocols for Use in Streams and Wadeable Rivers: Periphyton, Benthic Macroinvertebrates and Fish. EPA 841-B-99-002, second ed. U.S. Environmental Protection Agency; Office of Water, Washington, D.C.

Boxall, A.B.A., Brown, C.D., Barrett, K.L., 2002. Higher-tier laboratory methods for assessing the aquatic toxicity of pesticides. Pest Management Science 58 CP1-646.

CCME, 2007. Canadian Water Quality Guidelines: Imidacloprid. Scientific Supporting Document. Canadian Council of Ministers of the Environment, Winnipeg.

Callisto, M., Goncalves, J.F., Graça, M.A.S., 2007. Leaf litter as a possible food source for chironomids (Diptera) in Brazilian and Portuguese headwater streams. Revista Brasileira De Zoologia 24, 442-448.

Caquet, T., Hanson, M.L., Roucaute, M., Graham, D.W., Lagadic, L., 2007. Influence of isolation on the recovery of pond mesocosms from the application of an insecticide. II. Benthic macroinvertebrate responses. Environmental Toxicology and Chemistry 26, 1280-1290.

Cole, M.B., Arnold, D.E., Watten, B.J., 2001. Physiological and behavioral responses of stonefly nymphs to enhanced limestone treatment of acid mine drainage. Water Research 35, 625-632.

Coors, A., Kuckelkorn, J., Hammers-Wirtz, M., Strauss, T., 2006. Application of in-situ bioassays with macrophytes in aquatic mesocosm studies. Ecotoxicology 15, 583-591.

Crane, M., 1997. Research needs for predictive multispecies tests in aquatic toxicology. Hydrobiologia 346, 149-155.

Culp, J.M., Baird, D.J., 2006. Establishing cause-effect relationships in multi-stressor environments. In: Hauer, F.R., Lamberti, G.A. (Eds.), Methods in Stream Ecology, second ed. Elsevier Academic Press, Boston, USA, pp. 835-854.

Culp, J.M., Cash, K.J., Glozier, N.E., Brua, R.B., 2003. Effects of pulp mill effluent on benthic assemblages in mesocosms along the Saint John River, Canada. Environmental Toxicology and Chemistry 22, 2916-2925.

Ericksen, C.H., Resh, V.H., Lamberti, G.A., 1996. Aquatic insect respiration. In: Aquatic Insects of North America, third ed. Kendall, Hunt Publishing Company, Dubuque, Iowa, pp. 29-39.

Fairchild, J.F., Lapoint, T.W., Zajicek, J.L., Nelson, M.K., Dwyer, F.J., Lovely, P.A., 1992. Population-level, community-level and ecosystem-level responses of aquatic mesocosms to pulsed doses of a pyrethroid insecticide. Environmental Toxicology and Chemistry 11, 115-129.

Fossen, M., 2006. Environmental fate of imidacloprid. California Department of Pesticide Regulation.

Genkai-Kato, M., Nozaki, K., Mitsuhashi, H., Kohmatsu, Y., Miyasaka, H. Nakanishi, M., 2000. Push-up response of stonefly larvae in low-oxygen conditions. Ecological Research 15, 175-179.

Graça, M.A.S., 2001. The role of invertebrates on leaf litter decomposition in streams - a review. International Review of Hydrobiology 86, 383-393.

Gupta, S., Gajbhiye, V.T., Kalpana, Agnihotri N.P., 2002. Leaching behavior of imidacloprid formulations in soil. Bulletin of Environmental Contamination and Toxicology 68, 502-508.
Hatch, A.C., Burton, G.A., 1999. Sediment toxicity and stormwater runoff in a contaminated receiving system: consideration of different bioassays in the laboratory and field. Chemosphere 39, 1001-1017.

Hickey, C.W., Golding, L.A., 2002. Response of macroinvertebrates to copper and zinc in a stream mesocosm. Environmental Toxicology and Chemistry 21, 1854-1863.

Hruska, K.A., Dube, M.G., 2004. Using artificial streams to assess the effects of metal-mining effluent on the life cycle of the freshwater midge (Chironomus tentans) in situ. Environmental Toxicology and Chemistry 23, 2709-2718.

Irving, E.C., Baird, D.J., Culp, J.M., 2003. Ecotoxicological responses of the mayfly Baetis tricaudatus to dietary and waterborne cadmium: implications for toxicity testing. Environmental Toxicology and Chemistry 22, 1058-1064.

Kreutzweiser, D., Good, K., Chartrand, D., Scarr, T., Thompson, D., 2007. Non-target effects on aquatic decomposer organisms of imidacloprid as a systemic insecticide to control emerald ash borer in riparian trees. Ecotoxicology and Environmental Safety 68, 315-325.

Lam, P.K.S., 1996. Effects of cadmium on the consumption and absorption rates of a tropical freshwater snail, Radix plicatulus. Chemosphere 32, 2127-2132.

Maltby, L., 1999. Studying stress: the importance of organism-level responses. Ecological Applications 9, 431-440.

Maltby, L., Clayton, S.A., Wood, R.M., McLoughlin, N., 2002. Evaluation of the Gammarus pulex in situ feeding assay as a biomonitor of water quality: robustness, responsiveness, and relevance. Environmental Toxicology and Chemistry 21, 361-368.

Mandaville, S.M., 2002. Benthic macroinvertebrates in freshwaters - taxa tolerance values, metrics and protocols. Soil and Water Conservation Society of Metro Halifax.

Matsuda, K., Buckingham, S.D., Kleier, D., Rauh, J.J., Grauso, M., Sattelle, D.B., 2001 Neonicotinoids: insecticides acting on insect nicotinic acetylcholine receptors. Trends in Pharmacological Sciences 22, 573-580.

McWilliam, R.A., Baird, D.J., 2002. Application of postexposure feeding depression bioassays with Daphnia magna for assessment of toxic effluents in rivers. Environmental Toxicology and Chemistry 21, 1462-1468.

Merrit, R.W., Cummins, K.W., 1996. Aquatic Insects of North America, third ed Kendall/Hunt Publishing Company, Dubuque, Iowa.

Mills, N.E., Semlitsch, R.D., 2004. Competition and predation mediate the indirect effects of an insecticide on southern leopard frogs. Ecological Applications 14, 1041-1054.

Minitab, I., 2000. Minitab statistical software 13.0

Moffat, A.S., 1993. Agriculture - new chemicals seek to outwit insect pests. Science $261,550-551$

Pesacreta, G.J., 1997. Response of the stonefly Pteronarcys dorsata in enclosures from an urban North Carolina stream. Bulletin of Environmental Contamination and Toxicology 59, 948-955.

Pestana, J., Baird, D.J., Soares, A.M.V.M. Fear and loathing in the benthos: responses of aquatic insect larvae to the pesticide imidacloprid in the presence of chemical signals of predation risk, unpublished-a.

Pestana, J., Loureiro, S., Baird, D.J., Soares, A.M.V.M. Interactions between pesticide exposure and inducible antipredator responses in the zooplankton grazer, Daphnia magna Straus, unpublished-b.

Petersen, R.C., Cummins, K.W., 1974. Leaf processing in a woodland stream. Freshwater Biology 4, 343-368.

Relyea, R.A., Schoeppner, N.M., Hoverman, J.T., 2005. Pesticides and amphibians: the importance of community context. Ecological Applications 15, 1125-1134.

Rohr, J.R., Kerby, J.L., Sih, A., 2006. Community ecology as a framework for predicting contaminant effects. Trends in Ecology \& Evolution 21, 606-613.

Rosenberg, D.M., Resh, V.H., 1993. Freshwater Biomonitoring and Benthic Macroinvertebrates. Chapman and Hall, New York.

Ruesink, J.L., Srivastava, D.S., 2001. Numerical and per capita responses to species loss: mechanisms maintaining ecosystem function in a community of stream insect detritivores. Oikos 93, 221-234.

Schulz, R., Liess, M., 2001. Runoff simulation with particle-bound fenvalerate in multispecies stream microcosms: importance of biological interactions. Environmental Toxicology and Chemistry 20, 757-762.

Scrimgeour, G.J., Culp, J.M., Glozier, N.E., 1993. An improved technique for sampling lotic invertebrates. Hydrobiologia 254, 65-71.

Slijkerman, D.M.E., Baird, D.J., Conrad, A., Jak, R.G., van Straalen, N.M., 2004 Assessing structural and functional plankton responses to carbendazim toxicity. Environmental Toxicology and Chemistry 23, 455-462.

Song, M.Y., Stark, J.D., Brown, J.J., 1997. Comparative toxicity of four insecticides, including imidacloprid and tebufenozide, to four aquatic arthropods. Environmental Toxicology and Chemistry 16, 2494-2500.

Stoughton, S.J., Liber, K., Culp, J., Cessna, A., 2008. Acute and chronic toxicity of imidacloprid to the aquatic invertebrates Chironomus tentans and Hyalella azteca under constant- and pulse-exposure condition. Archives of Environmental Contamination and Toxicology, doi:10.1007/s00244-007-9073-6.

Tomizawa, M., Casida, J.E., 2005. Neonicotinoid insecticide toxicology: mechanisms of selective action. Annual Review of Pharmacology and Toxicology 45, 247-265.

Van den Brink, P.J., 2006. Response to recent criticism on aquatic semifield experiments: opportunities for new developments in ecological risk assessment of pesticides. Integrated Environmental Assessment and Management 2, 202-203.

Van den Brink, P.J., et al., 2005. The use of terrestrial and aquatic microcosms and mesocosms for the ecological risk assessment of veterinary medicinal products. Environmental Toxicology and Chemistry 24, 820-829.

Zar, J.H., 1996. Biostatistical Analysis. Prentice-Hall International, Inc., New Jersey. 